\title{
A robust coupling algorithm applied to thermal ice protection system unsteady modeling
}

\author{
Rémi Chauvin* \\ Philippe Villedieu ${ }^{\dagger}$ \\ Pierre Trontin $\ddagger$ \\ ONERA, Toulouse, 31000, France
}

\begin{abstract}
The aim of the present paper is to propose a general methodology for the numerical modelling of both anti and de-icing systems. A lubrication model is used for dealing with the dynamics of the runback water film. As regards thermal effects, in order to take into account heat conduction and unsteadiness, a parabolic temperature profile is assumed with respect to the normal coordinate for the ice layer. Heat transfers in the airfoil solid structure are described using a dedicated solver based on the unsteady heat conduction equation. The most original contribution of this work is the new technique (herein referred to as the "improved Schwarz method") which is proposed for coupling in a robust way the accretion-runback model and the solid heat conduction model. This new coupling algorithm allows to ensure fast convergence of both temperature and heat flux at the coupling interface (airfoil outer surface) and can be used either for steady state computations (anti-icing mode) or unsteady computations (de-icing mode). Numerical test cases which have been performed so far are very promising and show the relevance of this new approach for real applications and 3D extension.
\end{abstract}

\begin{tabular}{cll} 
& \multicolumn{2}{c}{ Nomenclature } \\
$c$ & Specific heat & $\left(\mathrm{J} . \mathrm{K}^{-1}\right)$ \\
$D=\frac{\lambda}{\rho c}$ & Thermal diffusivity & $\left(\mathrm{m}^{2} . \mathrm{s}^{-1}\right)$ \\
$e$ & Airfoil thickness & $(\mathrm{m})$ \\
$h_{i}$ & Ice height & $(\mathrm{m})$ \\
$h_{w}$ & Liquid runback water film height & $(\mathrm{m})$ \\
$L_{m}$ & Latent heat of melting & $\left(\mathrm{J} . \mathrm{kg}^{-1}\right)$ \\
$L_{v}$ & Latent heat of vaporisation & $\left(\mathrm{J} . \mathrm{kg}^{-1}\right)$ \\
$\dot{m}$ & Mass flux & $\left(\mathrm{kg} \cdot \mathrm{m}^{-2} . \mathrm{s}^{-1}\right)$ \\
$p$ & External pressure & $(\mathrm{Pa})$ \\
$\widehat{T_{i}}=\frac{1}{h_{i}} \int_{0}^{h_{i}} T_{i}(z) d z$ & Ice average temperature (see Fig 1 & $(\mathrm{~K})$ \\
$\widehat{T}_{w}=\frac{1}{h_{w}} \int_{0}^{h_{w}} T_{w}(z) d z$ & Liquid film runback water average temperature & $(\mathrm{K})$ \\
$T_{i, 0}$ & Ice lower temperature & $(\mathrm{K})$ \\
$T_{i, 1}$ & Ice upper temperature & $(\mathrm{K})$ \\
$T_{m}$ & Melting temperature & $(\mathrm{K})$
\end{tabular}

*PhD student, Aerodynamics and Energetic Modeling Dept., BP 40252 avenue Ed. Belin, Toulouse, F.

${ }^{\dagger}$ Senior Scientist, Aerodynamics and Energetic Modeling Dept., BP 40252 avenue Ed. Belin, Toulouse, F.

${ }^{\ddagger}$ Research engineer, PhD, Aerodynamics and Energetic Modeling Dept., BP 40252 avenue Ed. Belin, Toulouse, F. 


$\begin{array}{cll}v & \text { Liquid film velocity } & \left(\mathrm{m} \cdot \mathrm{s}^{-1}\right) \\ \lambda & \text { Thermal conductivity } & \left(\mathrm{W} \cdot \mathrm{m}^{-1} \cdot \mathrm{K}^{-1}\right) \\ \mu & \text { Dynamic viscosity } & (\mathrm{Pa} \cdot \mathrm{s}) \\ \nu & \text { Kinetic viscosity } & \left(\mathrm{m}^{2} \cdot \mathrm{s}^{-1}\right) \\ \dot{\Phi} & \text { Energy flux } & \left(\mathrm{W} \cdot \mathrm{m}^{-2}\right) \\ \rho & \text { Density } & \left(\mathrm{kg} \cdot \mathrm{m}^{-3}\right) \\ \tau_{g} & \text { External shear stress } & (\mathrm{Pa})\end{array}$

$\begin{array}{cl}\text { Subscript } & \\ \text { i } & \text { Ice } \\ \text { w } & \text { Liquid water } \\ \text { imp } & \text { impinging droplet } \\ \text { ev } & \text { evaporation } \\ \text { s } & \text { solid airfoil }\end{array}$

\section{Introduction}

Icing has long been recognized as an important issue in aeronautics. For instance, a thin ice layer on an airfoil can significantly reduce its lift and increase its drag. Consequently, aerospace industry has developed systems to address the problem. For anti-icing system, the ice is totally prevented from formation using application of heat, whereas for de-icing system, the ice may be allowed to form to a tolerable thickness and is regularly removed ${ }^{1]}$ For anti-icing systems, heat is produced using electrothermal or bleed air systems. For de-icing ones, in order to shed ice, thermal systems may also be used as well as chemical or mechanical (inflatable boots) systems.

Numerous works have been done for modelling ice accretion and runback film with or without a protection system. Regarding especially anti-icing systems, experimental investigations have long been made. Henry ${ }^{2}$ used an infrared thermography in order to measure the skin airfoil temperature in icing conditions with an activated electrothermal anti-icing system. Wright ${ }^{6}$ presented a review of heat transfer correlations that have been published for piccolo tube anti-icing systems (bleed air systems). He integrated these correlations into LEWICE code and compared numerical results with experiments. More recently, Papadaki ${ }^{3}$ investigated the piccolo system of a business jet wing in NASA Glenn Icing Research Tunnel. The main objective of these studies was to generate databases for the development and validation of thermal and icing analysis codes. Furthermore, models have been developed and numerically implemented for bleed air systems. For the accretion part, those models are essentially based on Messinger ${ }^{1}$ approach, that is to say a mass and an energy balance equation. Messinger's original model has been improved to include heat fluxes coming from the wall and take into account the dynamic of the runback water film. Morency et al. ${ }^{4}$ used shallow water equations to model the thin film, considering shear and pressure gradient forces due the aerodynamic flow. Airfoil region is modelled assuming that the thickness between the internal and external airfoil surfaces is so thin that the temperature may be assumed constant along the normal direction. Heat diffusion equation has to be solved only along the tangential direction. Conversely, Silveira et al. ${ }^{7}$ proposed to model heat diffusion in a multilayer material assuming heat diffusion along the tangential direction may be neglected.

The aim of the present paper is to propose a general methodology for the numerical modelling of both anti and de-icing systems. A lubrication model is used for dealing with the dynamics of the runback water film. As regards thermal effects, in order to take into account heat conduction and unsteadiness, a parabolic temperature profile is assumed with respect to the normal coordinate for the ice layer. Heat transfers in the airfoil solid structure are described using a dedicated solver based on the unsteady heat conduction equation. The most original contribution of this work is the new technique (herein referred to as the "improved Schwarz method") which is proposed for coupling in a robust way the accretion-runback model and the solid heat conduction model. This new coupling algorithm allows to ensure fast convergence of both temperature and heat flux at the coupling interface (airfoil outer surface) and can be used either for steady state computations (anti-icing mode) or unsteady computations (de-icing mode). Numerical test cases which have been performed so far are very promising and show the relevance of this new approach for real applications and 3D extension. 
The following of the paper is divided into 3 parts. The next section is devoted to the presentation of the model. The coupling algorithm is described in section III. Finally, the results of several numerical test cases are presented in section [V] and the accuracy and efficiency of the new proposed methodology are analyzed and commented.

\section{Ice protection system model}

In order to simulate an ice protection system, several phenomena have to be taken into account. Firstly, the external flow and the boundary layer must be computed. Then, a droplet trajectory computation has to be performed in order to get the mass flux reaching the wall. At this stage, impingement regimes may be accounted for. For instance, it is common to consider that a droplet may stick, bounce or splash, depending on its kinetic energy and its surface tension energy. This allows to compute the collection efficiency $(\beta)$. Outcomes of the aerodynamic and trajectory computations are then used as inputs for the accretion and runback model.

In this paper, we shall focus on ice accretion and water film runback and evaporation, and as well on heat conduction in the airfoil solid wall due to the presence of the thermal ice protection system (which may be a bleed air system or an electrothermal one).

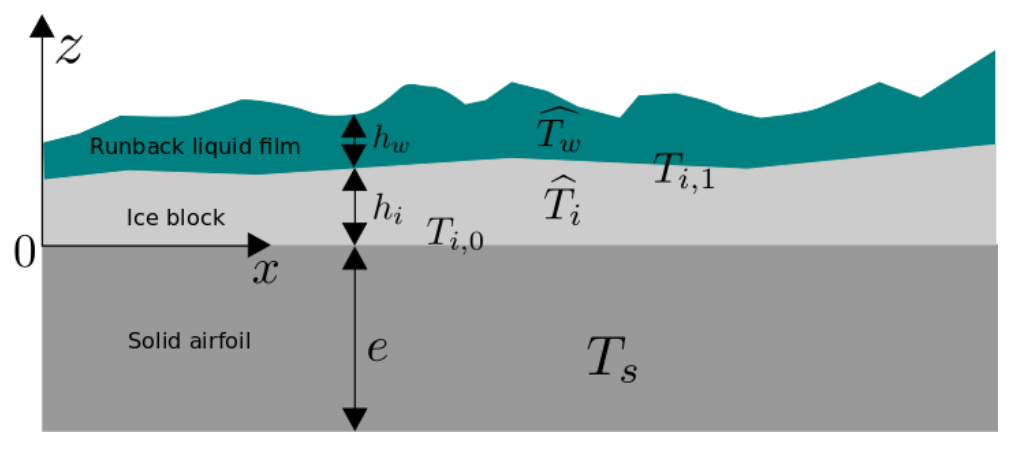

Figure 1. Illustration of modeled system

\section{A. General assumptions}

The model that we used relies on the following assumptions:

(i) Mass conservation is satisfied across each interface (air / ice or water layer interface and ice / water layer interface)

(ii) Energy conservation is satisfied across each interface

(iii) The effect of temperature on the viscosity $\mu_{w}$, density $\rho_{w}$, heat conductivity $\lambda_{w}$ and specific heat capacity $c_{w}$ of water is relatively small; therefore they may be taken as constant.

(iv) The effect of temperature on the density $\rho_{i}$, heat conductivity $\lambda_{i}$ and specific heat capacity $c_{i}$ of ice is relatively small; therefore they may be taken as constant.

(v) The liquid film Reynolds number $R e=\frac{v h_{w}}{\nu_{w}}$ and the aspect ratio of the two layers $\left(\left\|\nabla h_{w}\right\|\right.$ and $\left.\left\|\nabla h_{i}\right\|\right)$ are small enough for the lubrication theory being employed.

(vi) Gravity and tension surface effects in the liquid film are assumed to be small.

(vii) The film and the ice layer thickness are assumed to be thin enough for the conduction along the tangential direction to be neglected with respect to conduction along the normal direction.

It is worth pointing out that no simplifying assumption is made as regards heat conduction in the airfoil solid wall (or in the heat protection system itself in case of an electrothermal system). This is an important 
difference compared to previous works $\$ 47$. It means that a specific heat conduction solver has to be used for modelling heat transfers inside the solid wall. This solver has to be coupled to the accretion-runback solver (eventually in an unsteady way when considering a de-icing system). The coupling methodology will be presented hereinafter in section (III)

\section{B. Ice accretion model: mass and energy balance}

\section{Runback water film}

Impinging water droplets may either freeze or evaporate or form a liquid film. Since an unsteady model is required at least for de-icing system simulation, Messinger's original model cannot be used here. Instead, a "one equation shallow water model" has been introduced. This model is accurate as long as lubrication theory is verified (assumption (v)). According to this theory, the mass conservation equation reads:

$$
\frac{\partial \rho_{w} h_{w}}{\partial t}+\frac{\partial \rho_{w} q_{w}}{\partial x}=\dot{m}_{\mathrm{imp}}-\dot{m}_{\mathrm{ev}}-\dot{m}_{\mathrm{i}}
$$

where $q$ denotes the convective flux.

$$
q_{w}=\int_{h_{i}}^{h_{i}+h_{w}} v_{x}(z) d z=\left(\frac{\tau_{g}}{2}-\frac{\partial_{x} p}{3} h_{w}\right) \frac{h_{w}^{2}}{\mu_{w}}
$$

Regarding energy conservation modeling, a same kind of approach may be used. As in icing conditions liquid water films are necessarily very thin, a mean temperature model is used.

In the running wet case (no ice layer upon the solid wall), the general form of the energy conservation equation reads:

$$
\begin{aligned}
\frac{\partial \rho_{w} h_{w}\left(c_{w}\left(\widehat{T_{w}}-T_{m}\right)+L_{m}\right)}{\partial t}+\frac{\partial}{\partial x}\left(\rho_{w} Q_{w}\right)= & \dot{m}_{\mathrm{imp}}\left(c_{l}\left(T_{\mathrm{imp}}-T_{m}\right)+L_{m}\right) \\
& -\dot{m}_{\mathrm{ev}} \cdot\left(c_{l}\left(\widehat{T_{w}}-T_{m}\right)+L_{m}\right) \\
& +\dot{\Phi}_{\mathrm{conv}}-\dot{m}_{\mathrm{ev}} L_{v} \\
& +\dot{\Phi}_{\mathrm{wall}}
\end{aligned}
$$

where $Q_{w}$ denotes the convective flux

$$
Q_{w}=\int_{h_{i}}^{h_{i}+h_{w}} v_{x}(z)\left(c_{w}\left(\widehat{T_{w}}-T_{m}\right)+L_{m}\right) d z=q_{w}\left(c_{w}\left(\widehat{T_{w}}-T_{m}\right)+L_{m}\right)
$$

In the glaze accretion case, $\widehat{T_{w}}$ is assumed to be equal to the melting temperature. Hence, no energy equation has to be solved for the liquid water film and (3) simply reduces to

$$
\widehat{T_{w}}=T_{m}
$$

\section{Ice layer}

The same principles are applied for the ice mass and energy conservation equations. However, a constant temperature profile may not be used here because the ice layer can be much thicker than the liquid one. A linear profile assumption would be too restrictive because it would impose heat fluxes to be equal at liquid-ice and ice-wall interfaces. To overcome this constraint and to limit the complexity of the model, a parabolic profile has been chosen (three degrees of freedom). Therefore, the temperature profile at a given $\mathrm{x}$ location reads:

$$
T_{i}(x, z)=T_{i, 0}+2\left(3 \widehat{T}_{i}-2 T_{i, 0}-T_{i, 1}\right) \frac{z}{h_{i}}+3\left(T_{w, 1}+T_{w, 0}-2 \widehat{T}_{i}\right)\left(\frac{z}{h_{i}}\right)^{2}
$$


It is worth noticing that due to the boundary conditions, the only real degree of freedom is the average temperature $\widehat{T}_{i}$. In case of glaze ice accretion (presence of a liquid film over the ice layer), equations read:

$$
\left\{\begin{aligned}
\frac{\partial \rho_{i} h_{i}}{\partial t} & =\dot{m}_{\mathrm{i}} \\
\frac{\partial \rho_{i} h_{i} c_{i}\left(\widehat{T}_{i}-T_{m}\right)}{\partial t} & =\left.\lambda_{i} \frac{\partial T_{i}}{\partial z}\right|_{z=h_{i}}+\dot{\Phi}_{\text {wall }}
\end{aligned}\right.
$$

$\dot{m}_{\mathrm{i}}$ is computed using the Stefan condition

$$
\dot{m}_{\mathrm{i}} L_{m}=\left.\lambda_{i} \frac{\partial T_{i}}{\partial z}\right|_{z=h_{i}}-\left.\lambda_{w} \frac{\partial T_{w}}{\partial z}\right|_{z=h_{i}}
$$

where $\left.\frac{\partial T_{i}}{\partial z}\right|_{z=h_{i}}$ is expressed using the parabolic profile assumption. Using the constant temperature assumption in the liquid film, we get $\left.\lambda_{w} \frac{\partial T_{w}}{\partial z}\right|_{z=h_{i}}=\dot{\Phi}_{\mathrm{conv}}-\dot{m}_{\mathrm{ev}} L_{v}+\dot{m}_{\mathrm{imp}} c_{l}\left(T_{\mathrm{imp}}-T_{m}\right)$.

\section{Airfoil solid wall heat conduction model}

In the solid part of the system, the heat conduction equation is used. It reads:

$$
\rho_{s} c_{s} \frac{\partial T_{s}}{\partial t}-\vec{\nabla}\left(\lambda_{s} \vec{\nabla} T_{s}\right)=S
$$

where $S$ is a source term which can be locally non zero when heater mats are activated (de-icing systems). Boundary conditions must be added to equation (9).

On lateral sides $\left(x=x_{\min }\right.$ and $\left.x=x_{\max }\right)$, heat losses are neglected and a homogeneous Neumann boundary condition is applied. On the lower side $(z=-e)$, the condition depends on the type of protection system which is considered. In case of a bleed air system, a Fourier type boundary condition is applied which reads:

$$
-\left.\lambda_{s} \frac{\partial T_{s}}{\partial z}\right|_{z=-e}=h_{\text {bleed }}\left(T_{\text {bleed }}-T_{s}\right)
$$

where $h_{\text {bleed }}$ denotes the internal heat transfer coefficient of the bleed air system and $T_{\text {bleed }}$ its reference temperature. In case of an electrothermal system, this boundary condition is simply replaced by a homogeneous Neumann condition.

A generalized Fourier condition is used along the interface between the airfoil wall and the accretion zone (liquid film or ice). It reads:

$$
\left.\lambda_{s} \frac{\partial T_{s}}{\partial z}\right|_{z=0}=h_{\text {num }}\left(T_{0}-T_{s}\right)+\Phi_{0}
$$

where $h_{\text {num }}, T_{0}$ and $\Phi_{0}$ are the numerical heat transfer coefficient, numerical reference temperature and numerical reference heat flux, respectively. This general boundary condition plays an important role in the coupling procedure which is described in the next section.

\section{Coupling algorithm: an improved Schwarz method}

\section{A. Motivations and general principles}

As already mentioned coupling a heat conduction code with an ice accretion solver could be of great interest for many icing applications. In particular, in case of anti-icing or de-icing modeling, it is more accurate to compute heat transfers inside the airfoil using a general heat conduction solver instead of using a simplified model which often yields important errors.

Therefore it is necessary to define a general and robust coupling methodology. It requires to write boundary conditions at the common interface, such as imposing temperatures and heat fluxes to be equal on both sides of the interface. But it is well known that respecting both those conditions is often a difficult problem. An existing technique consists in imposing the heat flux to the first domain (let it be the Neumann domain, in reference to Neumann boundary condition) and imposing the temperature to the second one (let 
it be the Dirichlet domain), until convergence occurs, i.e. until continuity of temperature and heat flux is verified. It is referred as a non overlapping Schwarz method in the literature, and it is inspired by a Schwarz demonstration ${ }^{9}$ of existence of heat diffusion equation solution in an arbitrary domain. A review of Schwarz methods is available in literature 10

Although this technique has the convenience of being rapid to implement, it presents at least two main disadvantages. The convergence is generally conditioned by the choice of Neumann and Dirichlet domains, and may in some cases never occur, whatever the chosen configuration. Moreover, when convergence occurs, it is generally very slow.

To overcome those drawbacks, a new technique is proposed in this article. It is inspired by Schwarz method but it is improved in order to increase its robustness and convergence speed. Instead of imposing the flux to a domain and the temperature to the other one, we impose a linear combination of both to each domain. The first advantage is that both domains have a symmetric role and no choice has to be made regarding which is the Neumann domain and which is the Dirichlet one.

\section{B. Principle of the improved Schwarz method}

Let first consider a pure heat conduction problem without mass transfer. The generalization to icing problems will be done afterwards.

Let $\Omega_{1}$ and $\Omega_{2}$ be two adjacent domains and $\Gamma$ the separation interface, as shown in the Fig 2

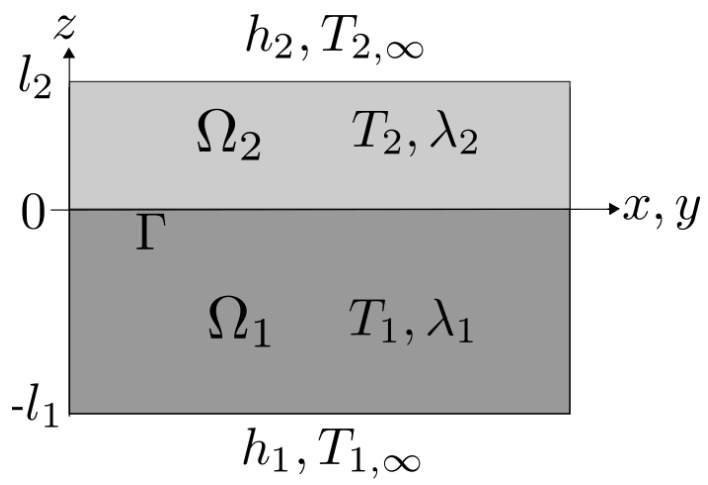

Figure 2. Abstract coupled thermal problem

Let assume that two independent unsteady heat conduction problems are posed on each domain and that these two problems are coupled through the interface by assuming continuity of the temperature and the heat flux.

Along the outer side of $\Omega_{2}$ domain, a Fourier type boundary condition is assumed:

$$
\Phi_{\mathrm{ent}}=h_{2}\left(T_{2, \infty}-T_{2}\left(l_{2}\right)\right)
$$

A same boundary condition is written along the inner side of $\Omega_{1}$ domain:

$$
\Phi_{\mathrm{ent}}=h_{1}\left(T_{1, \infty}-T_{1}\left(-l_{1}\right)\right)
$$

where $\Phi_{\text {ent }}$ denotes the entering flux : $\Phi_{\text {ent }}=\lambda \frac{\partial T}{\partial n}$

The purpose of the algorithm is to construct a sequence of $\left(T_{1}^{k}, T_{2}^{k}\right)$ converging toward the solution of the coupled problem. Let us introduce the following notations:

- $T_{1,0}$ and $T_{2,0}$ denote the interface temperatures on $\Omega_{1}$ side and $\Omega_{2}$ side, respectively.

- $\Phi_{1,0}$ and $\Phi_{2,0}$ denote the interface entering heat flux on $\Omega_{1}$ side and $\Omega_{2}$ side, respectively.

- $h_{\text {num }, 1}$ and $h_{\text {num }, 2}$ denote "numerical heat transfer coefficient" used for ensuring the convergence of the coupling algorithm. 
With those definitions, the improved Schwarz algorithm reads

Choose an arbitrary $T_{2,0}^{0}$ and $\Phi_{2,0}^{0}$

Repeat

- Solving the heat conduction problem in $\Omega_{1}$ using the following boundary condition on the coupling interface $\Gamma$

$$
\Phi_{1,0}^{k+1}=h_{\text {num }, 1}\left(T_{2,0}^{k}-T_{1,0}^{k+1}\right)-\Phi_{2,0}^{k}
$$

- Solving the heat conduction problem in $\Omega_{2}$ using the following boundary condition on the coupling interface $\Gamma$

$$
\Phi_{2,0}^{k+1}=h_{\mathrm{num}, 2}\left(T_{1,0}^{k}-T_{2,0}^{k+1}\right)-\Phi_{1,0}^{k}
$$

until ( Convergence occurs : $\left|\Phi_{1,0}^{k+1}+\Phi_{2,0}^{k+1}\right|$ and $\left|T_{1,0}^{k+1}-T_{2,0}^{k+1}\right|$ are small )

\section{Algorithm 1: Principle of the improved Schwarz algorithm}

Setting $h_{\text {num }, 1}=+\infty$ and $h_{\text {num }, 2}=0$, this algorithm degenerates to the basic non overlapping Schwarz method described in part A (with $\Omega_{1}$ as Dirichlet domain and $\Omega_{2}$ as Neumann domain). Thus, the improved Schwarz algorithm is a generalization of the basic one.

\section{Choice of the coupling numerical heat transfer coefficients}

For a 1D coupled heat conduction problem, using the fact that it is possible to compute the exact solution in each domain, a theoretical analysis of the above described algorithm can be carried out and will be presented in a forthcoming article ${ }^{[12}$ It leads to the following optimal choice for the coupling numerical heat transfer coefficients

$$
\left\{\begin{array}{c}
h_{\text {num }, 1}=\frac{\lambda_{2}}{\sqrt{D_{2} \Delta t}} \frac{\exp \left(\frac{2 l_{2}}{\sqrt{D_{2} \Delta t}}\right)\left(\frac{\lambda_{2}}{\sqrt{D_{2} \Delta t}}+h_{2}\right)-\left(\frac{\lambda_{2}}{\sqrt{D_{2} \Delta t}}-h_{2}\right)}{\exp \left(\frac{2 l_{2}}{\sqrt{D_{2} \Delta t}}\right)\left(\frac{\lambda_{2}}{\sqrt{D_{2} \Delta t}}+h_{2}\right)+\left(\frac{\lambda_{2}}{\sqrt{D_{2} \Delta t}}-h_{2}\right)} \\
h_{\text {num }, 2}=\frac{\lambda_{1}}{\sqrt{D_{1} \Delta t}} \frac{\exp \left(\frac{2 l_{1}}{\sqrt{D_{1} \Delta t}}\right)\left(\frac{\lambda_{1}}{\sqrt{D_{1} \Delta t}}+h_{1}\right)-\left(\frac{\lambda_{1}}{\sqrt{D_{1} \Delta t}}-h_{1}\right)}{\exp \left(\frac{2 l_{1}}{\sqrt{D_{1} \Delta t}}\right)\left(\frac{\lambda_{1}}{\sqrt{D_{1} \Delta t}}+h_{1}\right)+\left(\frac{\lambda_{1}}{\sqrt{D_{1} \Delta t}}-h_{1}\right)}
\end{array}\right.
$$

where $\Delta t$ denotes the time step used for the discretization of the heat conduction equation in both domains, using a first order implicit Euler scheme. These expressions are much simpler if one considers a steady heat conduction problem (which corresponds to the limit $\Delta t \rightarrow+\infty$ ). We get in that case:

$$
\left\{\begin{array}{l}
h_{\mathrm{num}, 1}=\left(\frac{1}{h_{2}}+\frac{l_{2}}{\lambda_{2}}\right)^{-1} \\
h_{\mathrm{num}, 2}=\left(\frac{1}{h_{1}}+\frac{l_{1}}{\lambda_{1}}\right)^{-1}
\end{array}\right.
$$

Using expressions (16) for $h_{\text {num,1 }}$ and $h_{\text {num,2, }}$, it can be shown that convergence occurs after only two iterations for the ideal 1D heat conduction problem. For real applications, due to 2D effects and additional effects such as evaporation, droplet impingement, etc, these expressions do not ensure convergence after a finite number of iterations but, as it will shown later, the method reveals to be robust and efficient. 


\section{Model Validation}

\section{A. Simulation of a bleed air anti-icing system tested in NASA IRT}

Numerical experiments are compared with a test case found in the literature. Experiments on a NACA23014 of a bleed air anti-icing system have been conducted in the NASA Icing Research Tunnel and compared with LEWICE by Wright. ${ }^{[6}$ The internal heat transfer coefficient $h_{\text {bleed }}$ and the reference bleed air temperature $T_{\text {bleed }}$ of the protection system were obtained by Wright using Goldstein correlation 11 External heat transfer coefficient and recovery temperature were obtained using the new 2D ONERA icing code IGLOO2D. The airfoil is $3.175 \mathrm{~mm}$ thick with a conductivity of $176.53 \mathrm{~W} \cdot \mathrm{m}^{-1} \cdot \mathrm{K}^{-1}$. The test case running conditions are summarized hereinafter

\begin{tabular}{|l|l|}
\hline Profile & NACA23014 \\
Chord $(m)$ & 1.52 \\
AOA $\left({ }^{\circ}\right)$ & 3 \\
$M_{\infty}$ & 0.18036 \\
$T_{\infty}\left({ }^{\circ} \mathrm{C}\right)$ & -5.35 \\
$P_{\infty}($ atm $)$ & 1 \\
MVD $(\mu m)$ & 29 \\
LWC $\left(g \cdot m^{-3}\right)$ & 0.87 \\
$T_{\text {bleed }}$ (anti-icing) $\left({ }^{\circ} \mathrm{C}\right)$ & 176.85 \\
\hline
\end{tabular}

Table 1. Test case ice accretion condition

The internal heat coefficient varies a lot in the span-wise direction because of the piccolo position. In Wright article, coefficients are given for three span-wise cuts.

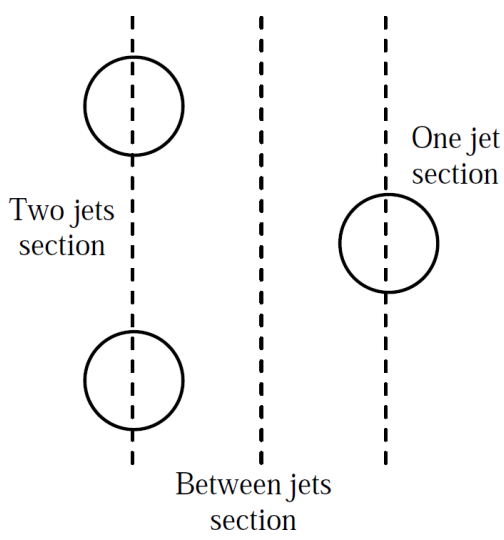

Figure 3. Selected wingspan positions for anti-icing system. Courtesy of Donatti et.a ${ }^{7}$

The corresponding values of the internal heat coefficients may be found in Wright article (figures have been digitized).

\section{Convergence of the coupling algorithm}

Although the test case being steady, it was simulated using an unsteady numerical approach with large time steps $(\Delta t=100 s)$. The final physical time has been arbitrarily fixed to 1000s. At each time step (excepted the first one) the values of the previous time step are used for initializing the coupling algorithm. For this reason, the algorithm converges very quickly excepted for the first time step.

Hereinafter, the figure shows the convergence history (in both $\mathbb{L}_{2}$ and $\mathbb{L}_{\infty}$ norms) corresponding to the first time step and the "between jets section" configuration (see Fig. 4). It can be seen that the convergence is not monotone. It seems to be due to some oscillations of the dry wall / running wet film limit. Work is still in progress to improve this feature. 
Time $=100.0 \mathrm{~s}$, iterations $=53$
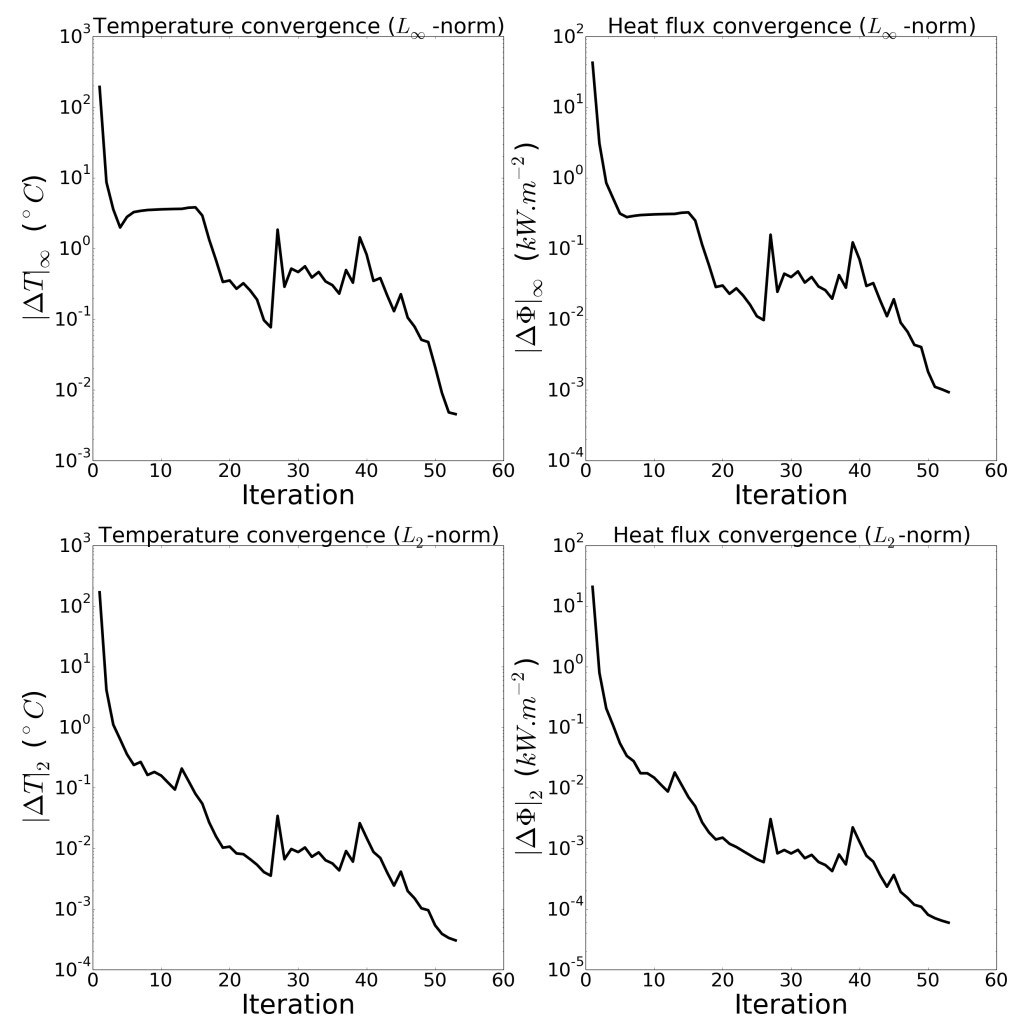

Figure 4. Convergence history of the improved Schwarz algorithm for the "between jets section" configuration at the first time step. Upper figures: $\mathbb{L}_{\infty}$ norm. Lower figures: $\mathbb{L}_{2}$ norm

\section{Comparison with Wright's numerical experiments}

Surface temperatures are compared with LEWICE simulation results (Wright) and Donatt ${ }^{\sqrt{7}}$ ones. Donatti used two different models for heat conduction inside the airfoil, referred as "1D normal" and "1D surface" formulation. Here we only compare with the 1D surface model, because it presents the convenience of modeling tangential heat conduction in the airfoil wall. Our model is referred as "ONERA model" in what follows. 


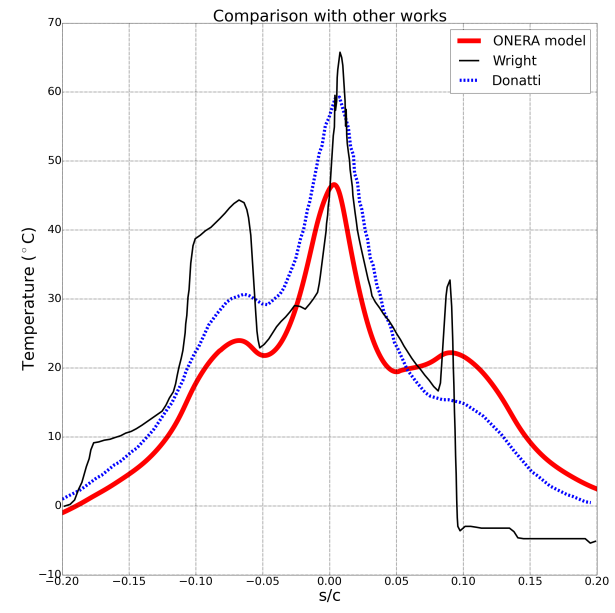

Figure 5. External temperature in case of the "two jets section" configuration

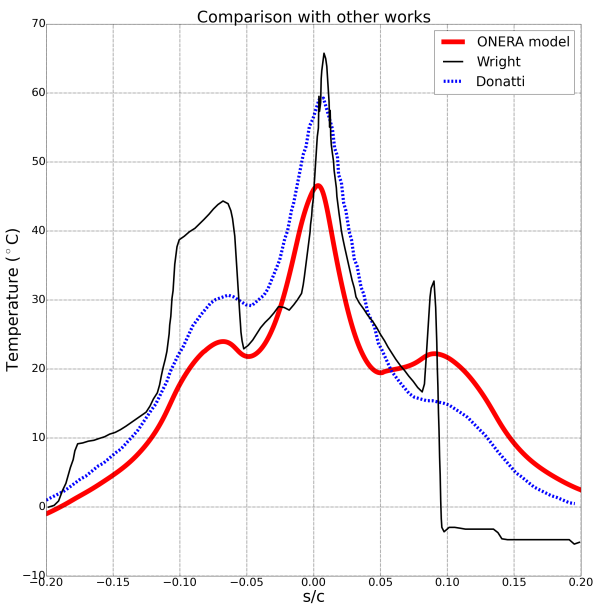

Figure 6. External temperature in case of the "one jet section" configuration 


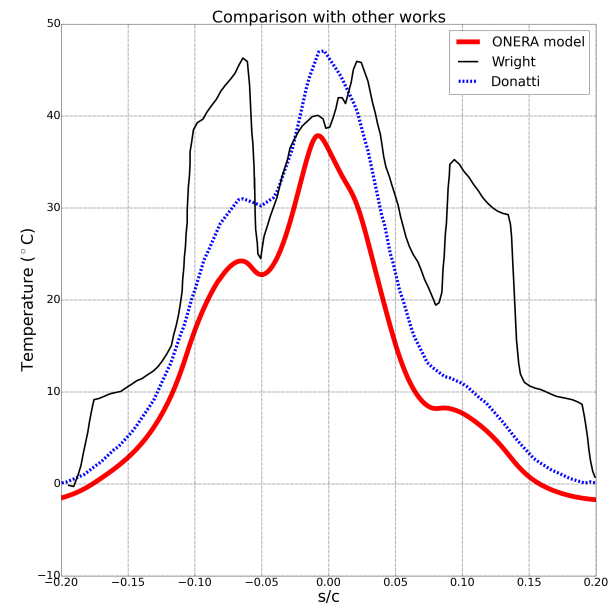

Figure 7. External temperature in case of the "between jets section" configuration

This comparison shows that, for all configurations, our model under-predicts wall temperatures compared to the published results (note that this conclusion would be the same if the results corresponding to Donatti "1D normal" model were presented). Moreover, our results are less oscillatory than those obtained by wright and Donatti. This could be due to the fact that heat conduction in the solid wall is better predicted in our approach which tends to homogenize the temperature distribution along the tangential direction.

\section{Comparison with NASA experimental results}

In Wright's article two span-wise cut experimental temperature profiles are available. Even if they do not exactly correspond to the sections for which the internal heat transfer coefficient is given, these profiles have been compared (see Fig. 3p to our numerical results. 


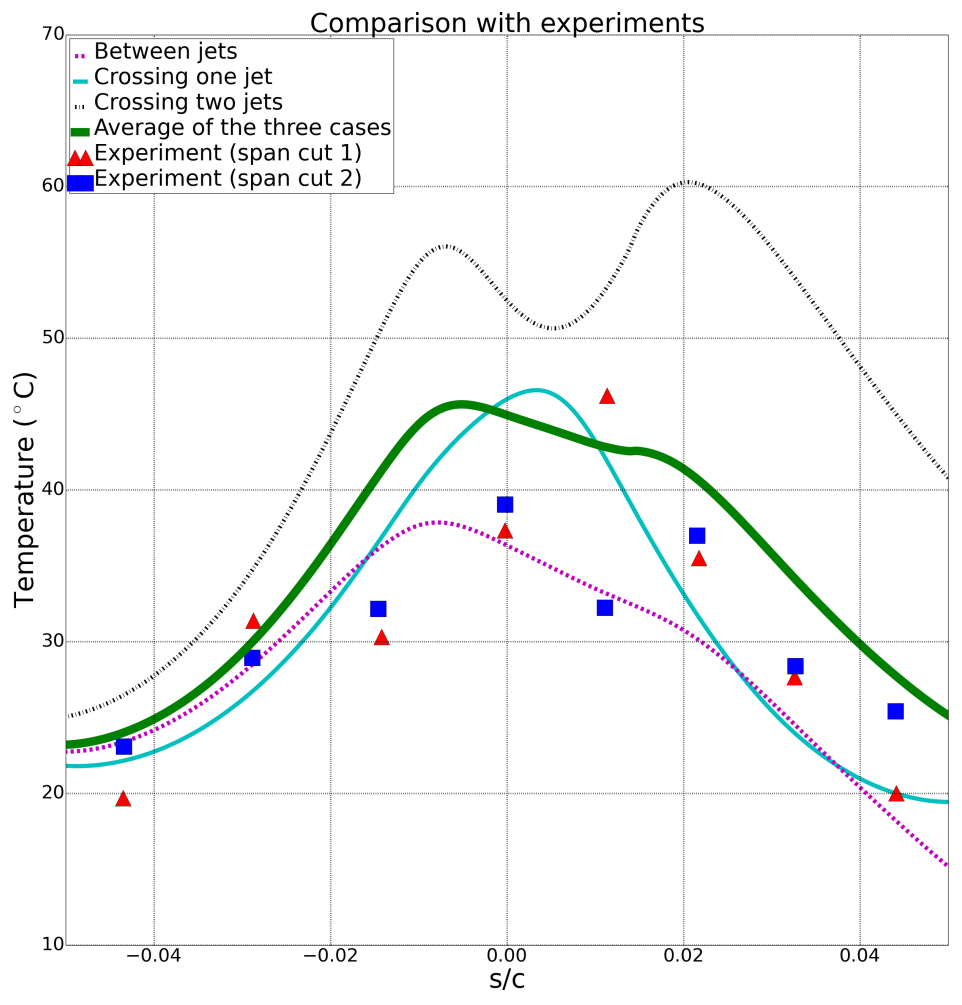

Figure 8. External temperature: ONERA model compared to experimental data

From a qualitative point of view, the comparison is very satisfactory. Due to the fact that our model is only $2 \mathrm{D}$, heat conduction along the span-wise direction is not taken into account. Hence it is logical to over-predict temperatures in the "two-jets section" configuration and conversely to under-predict them in the "between jets section" configuration. Consequently the green curve which corresponds to the average of the three configuration results is very close to the experimental points. A better agreement could not be expected here due to the number of inaccuracy sources (modeling of the internal and external heat transfer coefficients, 3D effects ...).

\section{B. Numerical investigation of the influence of wall heat conduction on ice shape}

\section{Motivations}

It is common to use Messinger model to perform an ice shape computation in the absence of an activated thermal protection system. In this model it is assumed that the ice layer is insulating enough so that the heat flux at the wall-ice interface may be neglected. This hypothesis is justified when the ice layer is thick enough. However, such an assumption may be unverified at the beginning of the accretion process, when the ice layer is very thin. Therefore, if the accretion time is relatively short, Messinger model overpredicts the runback film water.

In this part we present test cases in order to illustrate the difference between the Messinger model and the ONERA model and to see the influence of the heat conduction inside the wall on the ice shape. We focus on normal and tangential heat conduction as well as the wall thickness influence.

\section{Presentation of the test case}

We consider an NACA0012 profile in aluminium of chord c $(0.5334 \mathrm{~m})$ and thickness $e$. The data are detailed in the following table 


\begin{tabular}{|l|l|}
\hline Profile & NACA0012 \\
Chord $(m)$ & 0.5334 \\
AOA $\left({ }^{\circ}\right)$ & 4 \\
$M_{\infty}$ & 0.317 \\
$T_{\infty}\left({ }^{\circ} C\right)$ & -10.85 \\
$P_{\infty}(a t m)$ & 1 \\
MVD $(\mu m)$ & 20 \\
LWC $\left(g . m^{-3}\right)$ & 0.55 \\
\hline
\end{tabular}

Table 2. Test case ice accretion condition

For the ONERA model, a first pure heat conduction problem is performed before the computation in such a manner that the airfoil is in thermal equilibrium with the atmosphere. Then, the accretion is activated and an ice shape is formed.

\section{Influence of the normal heat conduction in the wall}

In this first test case only normal heat conduction in the airfoil is taken into account. Ice shapes for several airfoil thickness are plotted hereinafter in Fig 9 and Fig 10

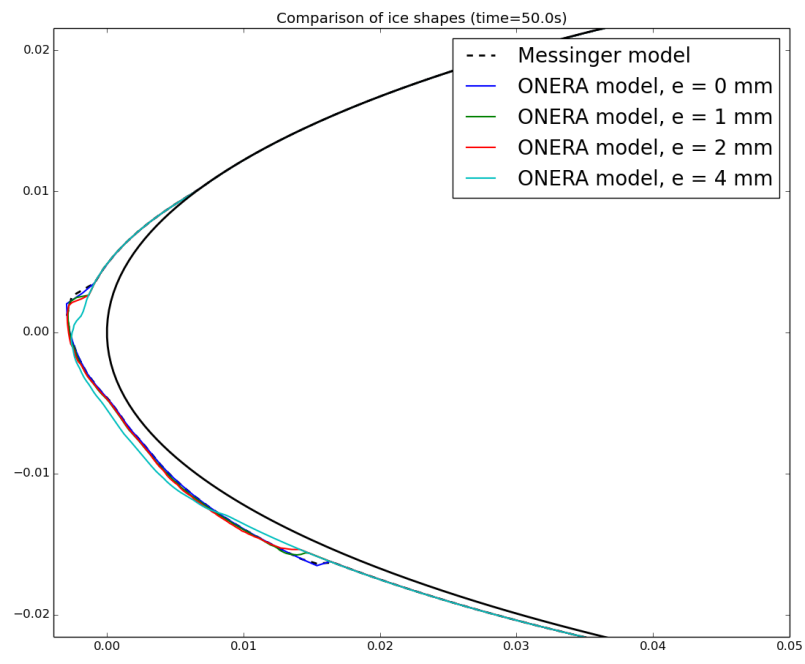

Figure 9. Ice shapes (50s of accretion)

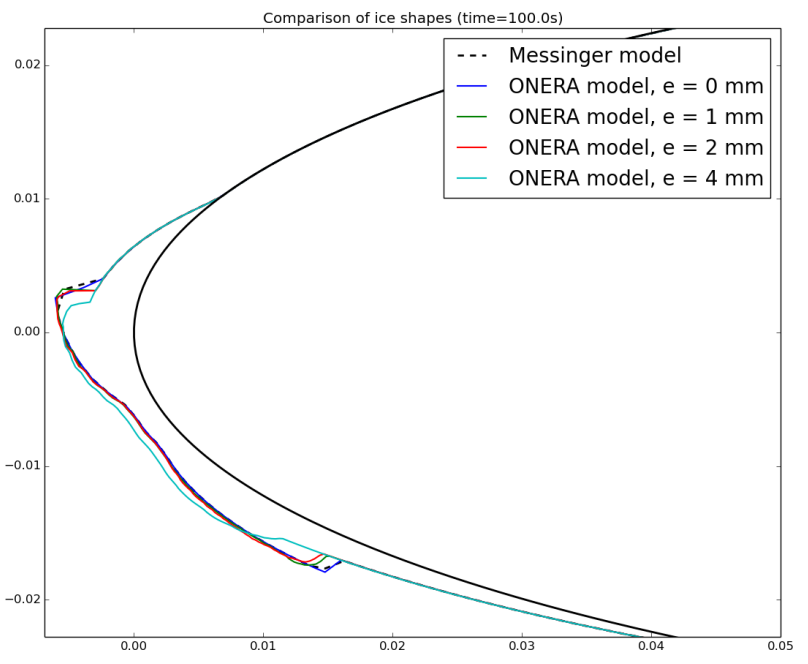

Figure 10. Ice shapes (100s of accretion)

As expected, one can see in the graph that the thicker the wall is, the thicker the ice close to the stagnation point is. The freezing rate is enhanced since heat is extracted from the ice layer by heat conduction in the wall.

We present ice heights (fig. 11 and 12 and wall temperature (fig. 13 and 14 ) at the beginning of accretion. For visual convenience, they are plotted as functions of the curvilinear abscissa (in $\mathrm{mm}$ ). 


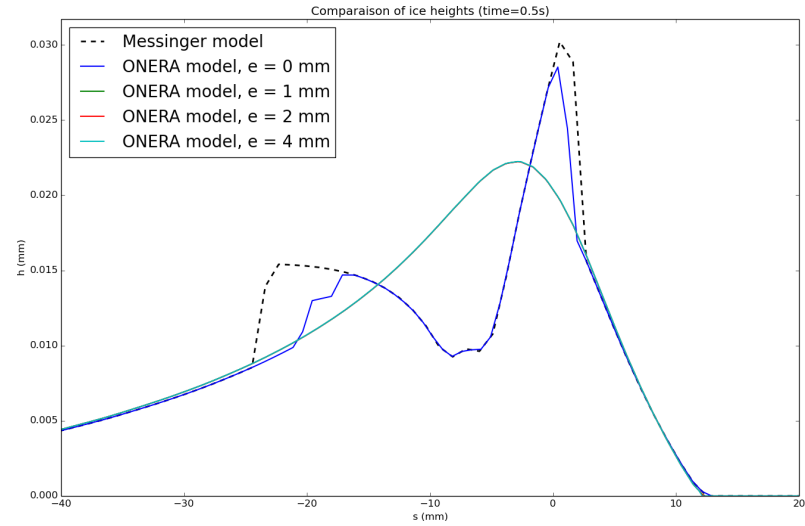

Figure 11. Ice heights (0.5s of accretion)

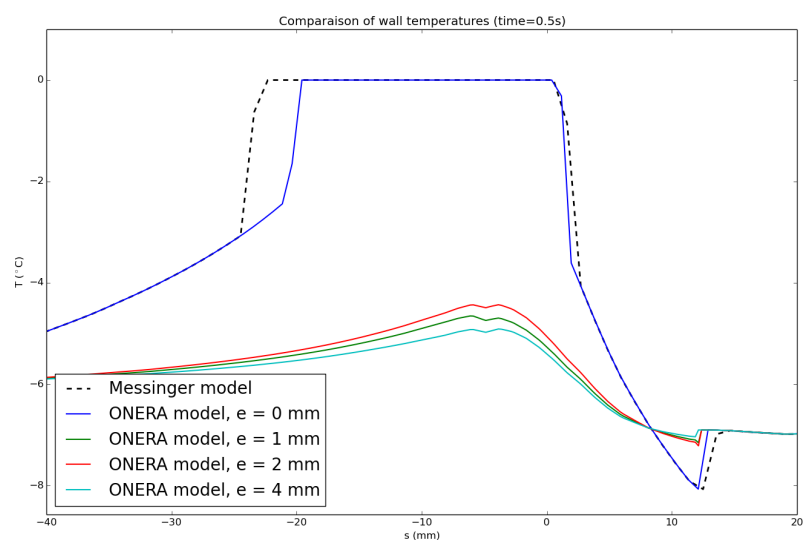

Figure 13. Wall temperature (0.5s of accretion)

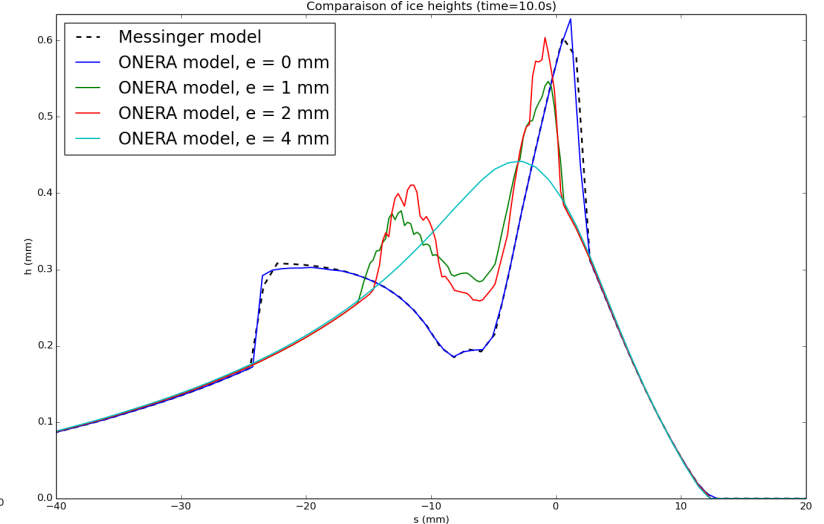

Figure 12. Ice heights (10s of accretion)

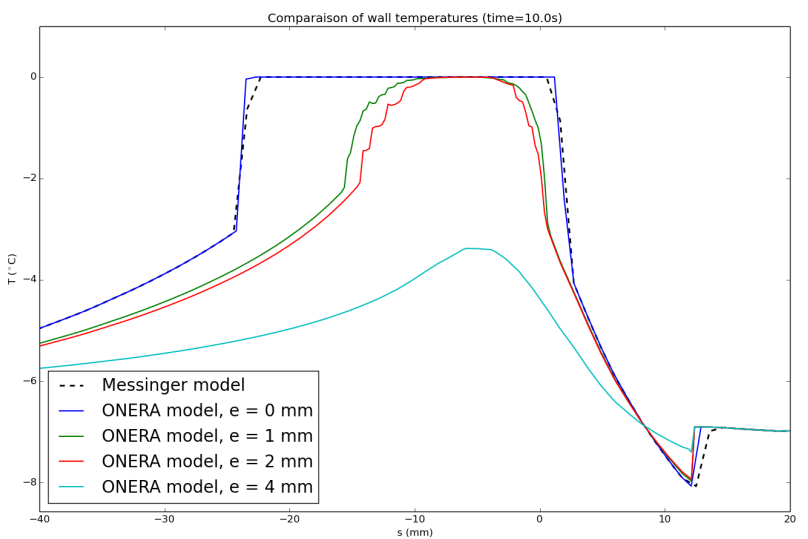

Figure 14. Wall temperature (10s of accretion)

- One may observe a difference between the Messinger model and the ONERA model without heat conduction into the wall. It is only due to the fact that the ONERA model takes into account the transient phase needed by the liquid film to reach a steady state while the Messinger model assumes this phenomenon is instantaneous.

- At the beginning of the accretion, the Messinger model predicts formation of glaze ice near the stagnation point whereas the ONERA model coupled with the thermal problem inside the airfoil predicts formation of rime ice. This is due to the fact that the airfoil temperature is lower that the freezing temperature when the first droplets impact and therefore the heat flux can not be neglected with respect to the convective heat flux exchanged with the external airflow. Convective and wall heat fluxes are plotted on the following graph (fig. 15 and 16 for the particular case $e=1 \mathrm{~mm}$ at some simulation time steps. It is clear that the wall flux is much greater than the convective one when accretion starts (dark blue curves) and become negligible for a long time of accretion (cyan curves). 


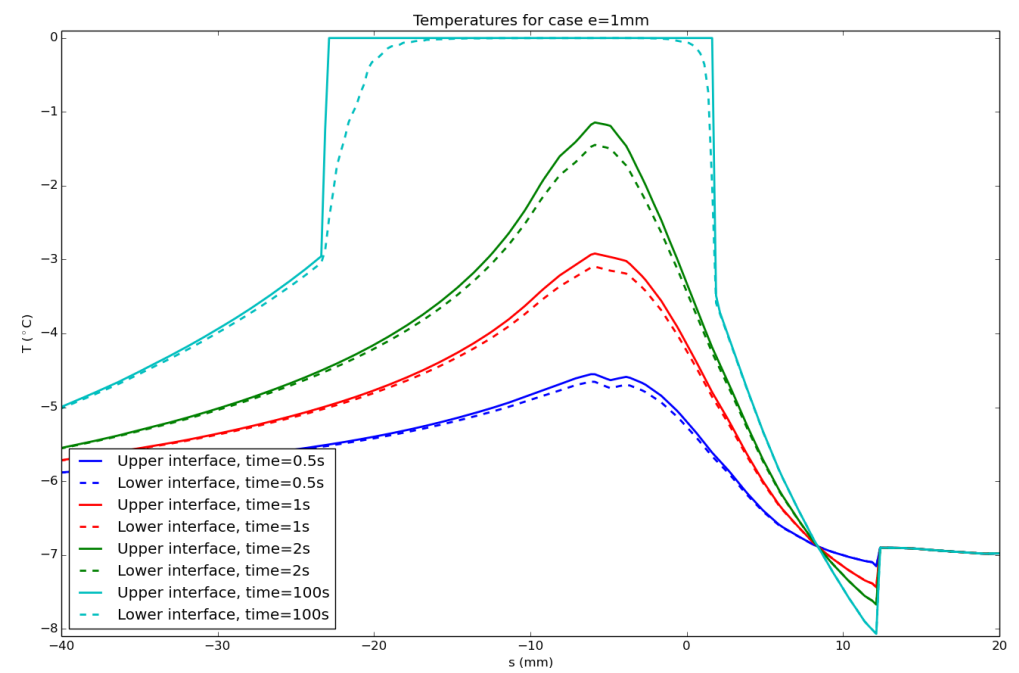

Figure 15. Temperatures of the ice block (upper and lower interfaces) for several simulation times $(e=1 \mathrm{~mm})$

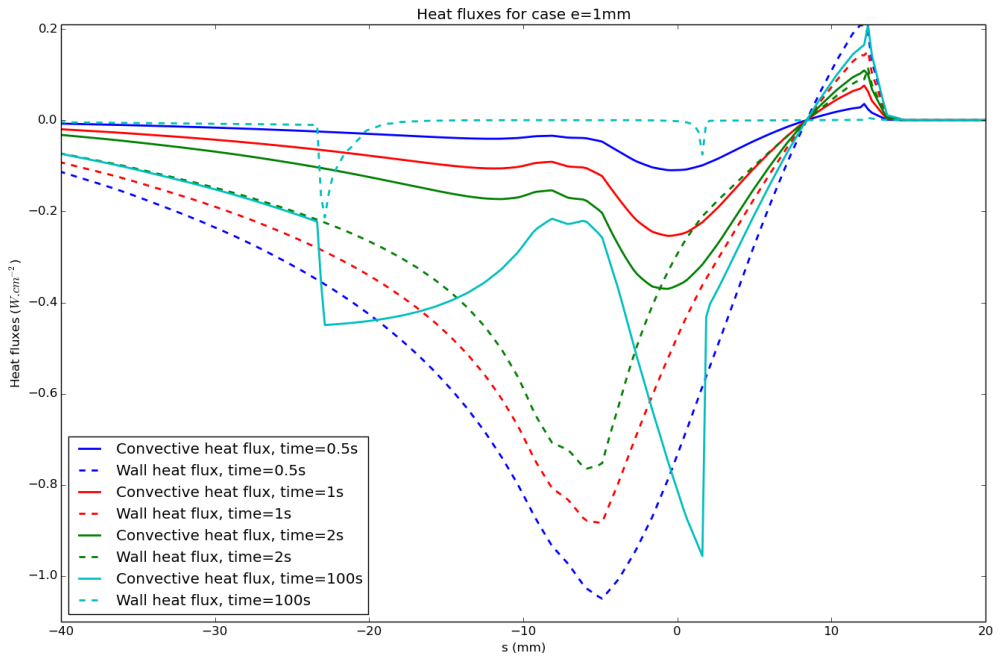

Figure 16. Heat fluxes at upper and lower interfaces of the ice block $(e=1 \mathrm{~mm})$

The difference between upper and lower temperatures may appear very small, especially at the beginning of the accretion process. However, it is important to keep in mind that the ice layer is very thin. That is why wall fluxes at the first simulation time steps are huge.

\section{Influence of the tangential heat conduction}

Unlike the previous test case, the heat conduction along the tangential direction is now activated. Obviously the normal heat conduction is still activated (otherwise no heat flux would be exchanged at the wall-ice interface).

Ice shapes for several airfoil thickness are plotted hereinafter 


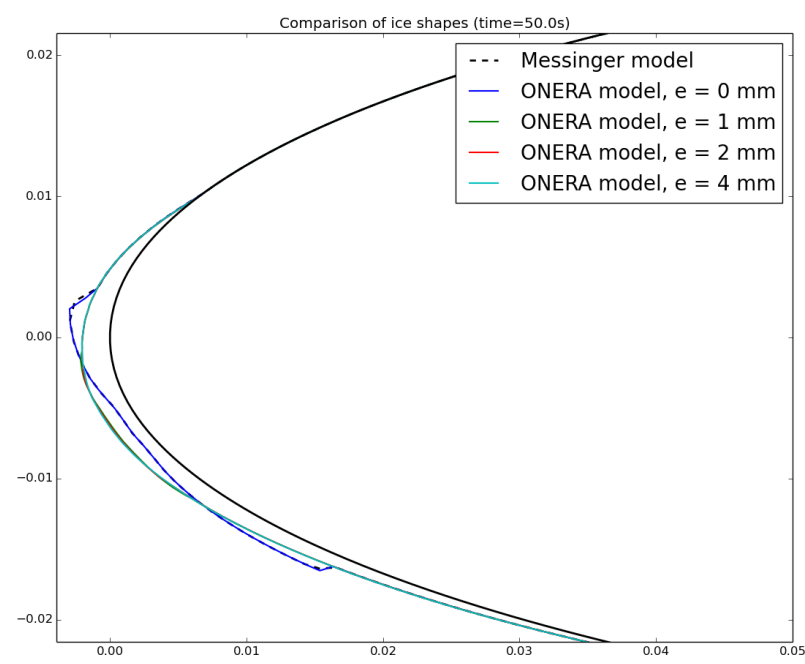

Figure 17. Ice shapes (50s of accretion)

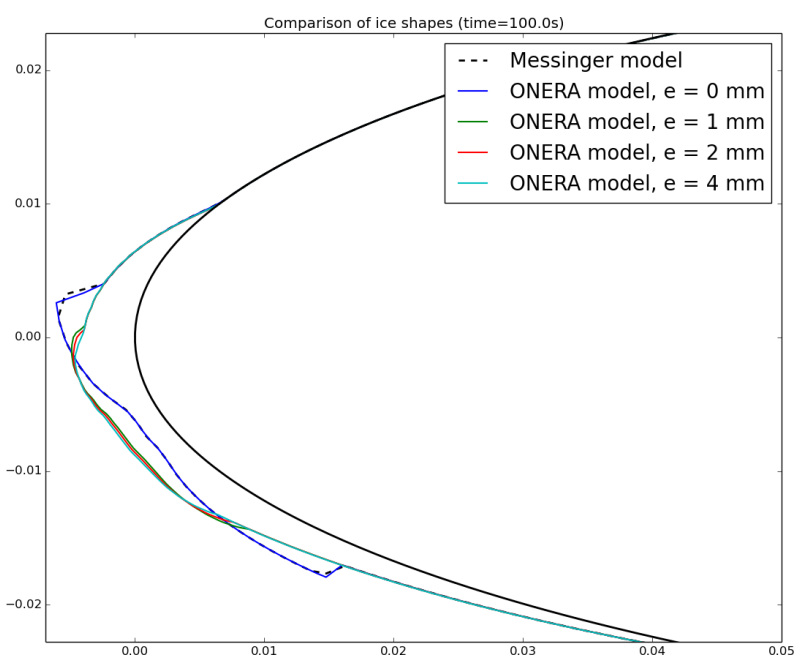

Figure 18. Ice shapes (100s of accretion)

One can see in those figures that the heat conduction along the tangential direction has a greater influence on the ice shape.

Actually, when tangential heat conduction is not taken into account, the temperature near the stagnation point rapidly reaches the melting temperature. Hence, no heat flux may exist at the wall-ice interface and the droplet latent heat of solidification may not be evacuated into the wall anymore. Thus, the Messinger model and the ONERA one become equivalent and the difference between ice shapes is only due to the transient stage.

However, in the current case, heat may be continuously evacuated from the ice layer to the wall thanks to the tangential heat conduction. Therefore the freezing rate is increased even after a long accretion time and the liquid fraction is strongly reduced.

Fig 19 and Fig 20 show the temperature field in the wall and illustrate the difference between the models with and without tangential heat conduction in the case of a $1 \mathrm{~mm}$ thick airfoil.
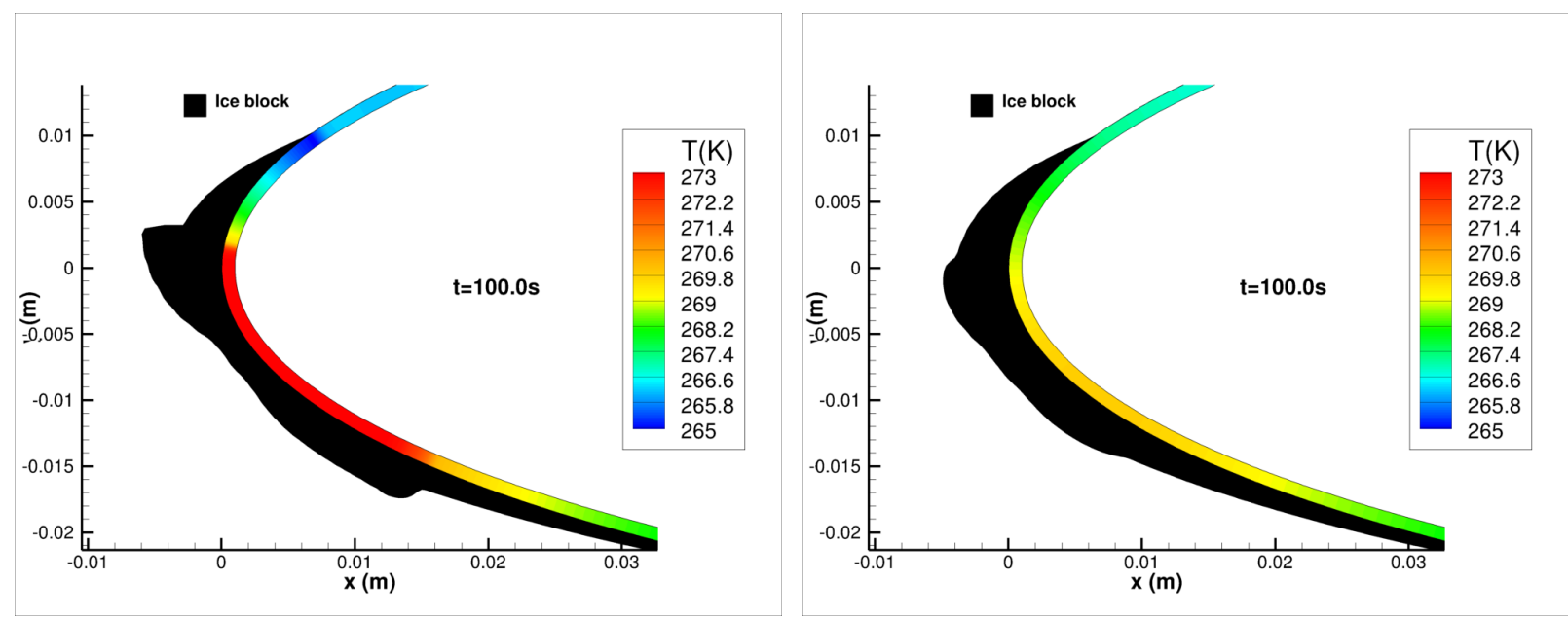

Figure 19. Ice shape and airfoil temperature Fig ( $e=1 \mathrm{~mm}$, tangential diffusion deactivated) ( $e=1 \mathrm{~mm}$, tangential diffusion activated) 
5. Rime-glaze transition near the stagnation point : temperature profiles

Looking at figures of the different accretion test cases presented above, it is clear that a rime to glaze transition occurs. Here are presented the normal temperature profiles in the ice at the stagnation point for several times. Transition to glaze ice is characterized by the upper surface temperature being equal to $0^{\circ} \mathrm{C}$. As expected this transition occurs sooner for the case without tangential heat conduction. It is also worth pointing out that in both cases temperature profiles are almost linear. The abscissa is the non dimensional height $z^{*}\left(z^{*}=z / h_{i}\right.$, where $h_{i}$ is the ice thickness).
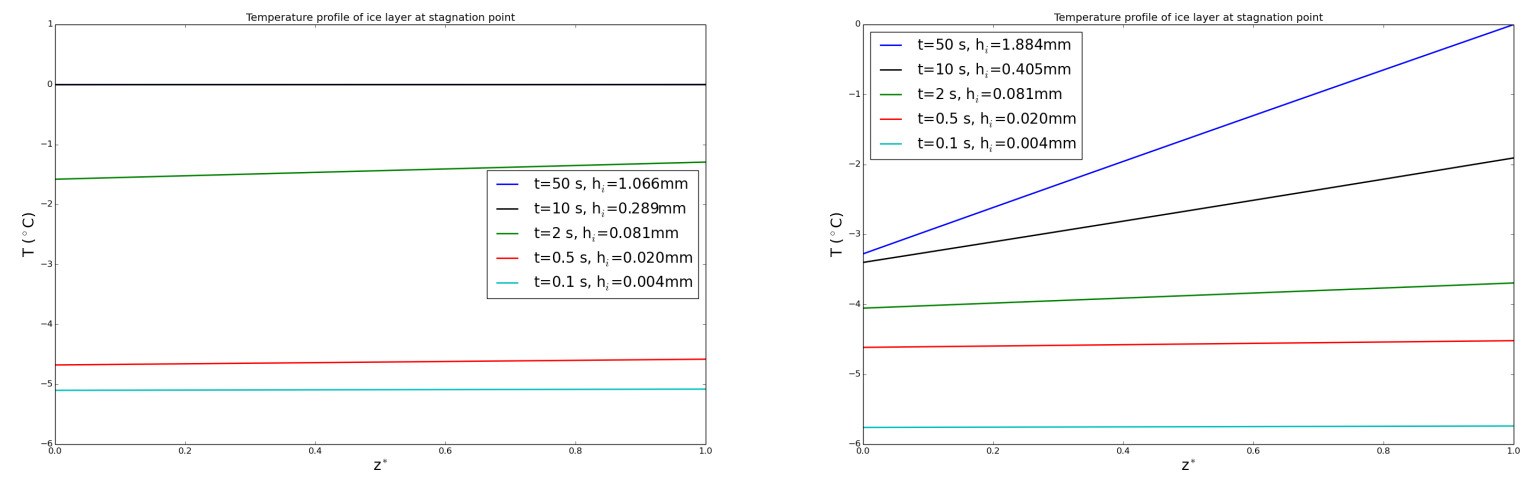

Figure 21. Temperature profiles of ice block along the ice thickness. Left : unactivated heat conduction. Right : activated heat conduction

\section{Simulation of runback ice accretion on a heated airfoil}

For this last test case, we consider a NACA0012 profile of chord $0.6 \mathrm{~m}$. The airfoil is $8.42 \mathrm{~mm}$ thick and four heater mats are located inside as shown in Fig. 22. The four heaters are maintained activated during all the calculation.

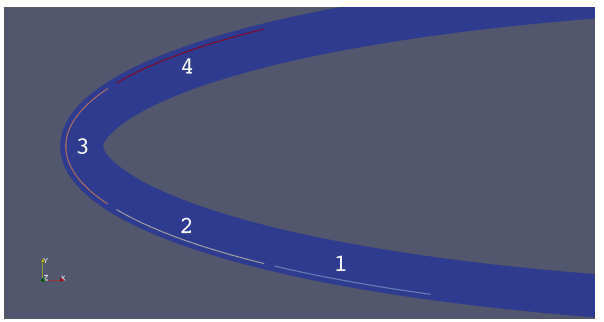

Figure 22. Heater mat location inside the airfoil

\begin{tabular}{|c|c|}
\hline Heater $\mathrm{n}^{\circ}$ & Power $\left(W . c m^{-2}\right)$ \\
\hline 1 & 1 \\
2 & 2 \\
3 & 2 \\
4 & 1 \\
\hline
\end{tabular}

Table 3. Heater mats power

\begin{tabular}{|c|c|}
\hline Profile & NACA0012 \\
Chord $(m)$ & 0.6 \\
AOA $\left({ }^{\circ}\right)$ & 4 \\
$M_{\infty}$ & 0.206 \\
$T_{\infty}\left({ }^{\circ} C\right)$ & -7.75 \\
$P_{\infty}(a t m)$ & 1 \\
MVD $(\mu m)$ & 20 \\
LWC $\left(g . m^{-3}\right)$ & 0.8 \\
\hline
\end{tabular}

Table 4. Test case data
Before starting accretion, a pure dry air heat conduction problem is performed. This computation is stopped when the thermal equilibrium between the airfoil (with activated heaters) and the air flow has been reached. External data are summarized in the following table. Fig 23 shows the temperature field in the heater at the end of this preliminary computation (just before droplet injection) and beginning of the accretion process. 
Fig 24 shows the temperature field inside the heater and the ice block shape after 50 seconds of accretion.
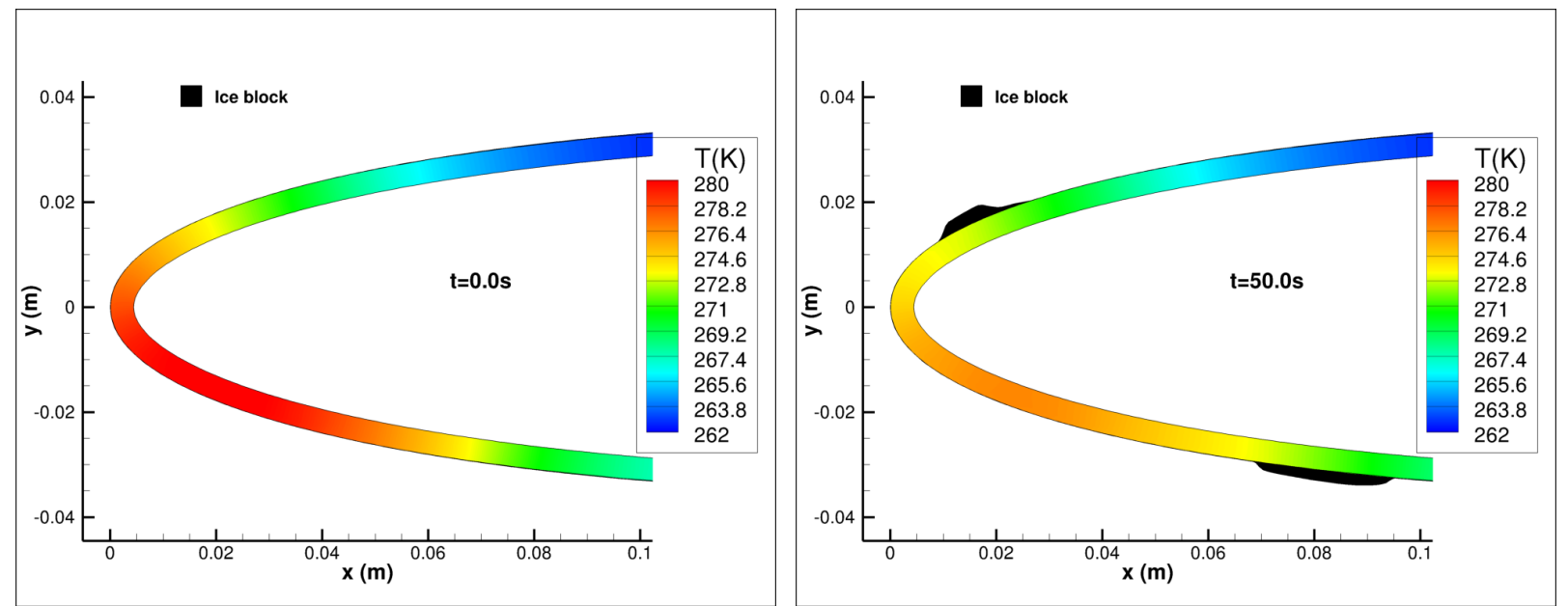

Figure 23. Airfoil temperature profile before ac- Figure 24. Ice shape after 50 s of accretion cretion ('dry air computation') (parabolic profile of temperature)

At the very beginning, the airfoil is hot ( $280 \mathrm{~K}$ near the stagnation point) because there is no droplet impact. Then, droplets impact the airfoil and cool it down. As the surface is too hot for the droplets to freeze, a thin liquid film forms and runs along the wall. This film freezes further in a less thermally protected area.

To check the importance of taking into account heat conduction in the ice layer, we also performed the same accretion test case but we replaced the parabolic model by a simplified model based on a uniform ice temperature profile. When considering glaze ice accretion, this model assumes that the ice temperature is equal to the melting temperature and that the heat flux at the ice-film interface is the same as the one computed at the wall-ice interface. Fig. 25) shows the ice shape obtained with the simplified model. It should be compared to Fig 24. The two shapes are very different but due to the lack of corresponding experimental it is not possible at this stage to conclude on which model is the more accurate. Further investigations are needed.

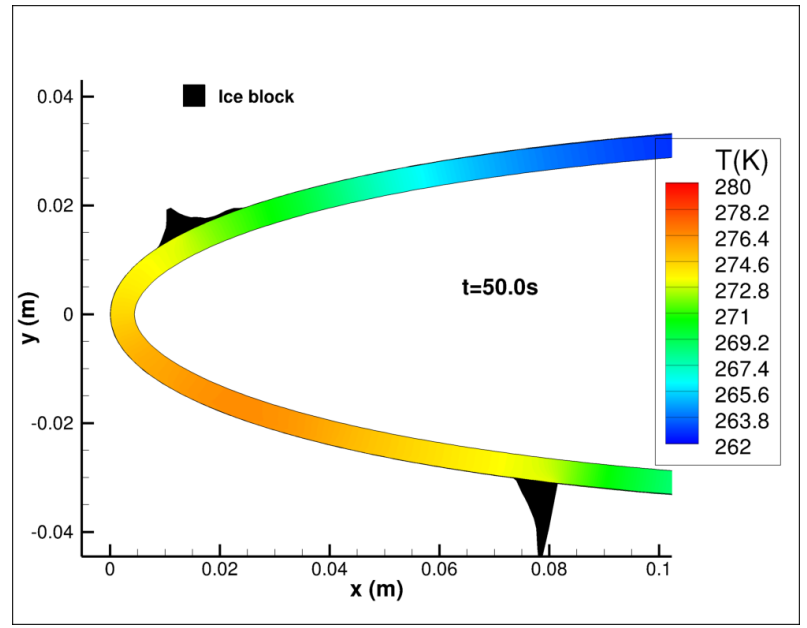

Figure 25. Ice shape after $50 \mathrm{~s}$ of accretion (constant profile of temperature) 


\section{Conclusion and future work}

A model for accretion and runback has been developed and implemented in the module FILM of IGLOO2D, the new ONERA 2D icing toolbox. It takes into account heat transfers across ice and liquid film layers as well as in the airfoil. So far the code has been used to simulate accretion on a cold wall by considering heat conduction inside the wall and anti-icing process with or without runback icing. It has been shown that heat conduction in the airfoil may have non negligible effects even in pure accretion. Furthermore, a general improved Schwarz algorithm has been developed to couple two independent thermal codes. This algorithm proves to be robust and fast even if both theoretical and numerical studies are in progress to assure a fast convergence in any case.

These promising results need to be strengthened by future validations using experimental databases. As regards physical modeling, future work will focus on improving the film dynamic model by taking into account capillary effects, rivulets and beads. Heat exchanges between the film and the atmosphere on the one hand, and between the film and the wall on the other, will also need to be modified.

\section{Acknowledgements}

The authors would like to thank L. Bennani for his contribution to the code development. The third author also acknowledges the funding support of the French Direction Générale de l'Armement.

\section{References}

\footnotetext{
${ }^{1}$ Messinger, B.L., "Equilibrium Temperature of an Unheated Icing Surface as a Function of Air Speed", Journal of the Aeronautical Sciences, Vol. 20, No. 1, 1953, pp. 2942

${ }^{2}$ Henry, R., "Étude du fonctionnement d'un dégivreur électrique : modélisation et mesures en soufflerie givrante de température pariétale par termographie infrarouge", PhD thesis, 1989

${ }^{3}$ Papadakis, M., Wong, S.H., Yeong, H.W, WONG, S.C., "Icing Tunnel Experiments with a Hot Air Anti-Icing System", 46th AIAA Aerospace Sciences Meeting and Exhibit, paper AIAA 2008-444

${ }^{4}$ Morency, F., Brahimi, M.T., Tezok, F., Paraschivoiu, I., "Hot air anti-icing sytem modelization in the ice prediction code CANICE", paper AIAA-98-0192

${ }^{5}$ Al-Khalil, K., Horvath, C., Miller, D., Wright, W., "Validation of Thermal Ice Protection Computer Codes: Part 3- The Validation of ANTICE", AIAA 35 $5^{\text {th }}$ Aerospace Sciences Meeting \& Exhibit, 1997 / Reno, NV

${ }^{6}$ Wright, W., "An Evaluation of Jet Impingement Heat Transfer Correlations for Piccolo Tube Application", paper AIAA2004-0062

${ }^{7}$ Donatti, C.N., Silveira, R.A., Bridi, G., Maliska, C.R., de Silva, A.F.C, "Ice accretion simulation in presence of a hot air anti-icing system", $19^{\text {th }}$ International Congress of Mechanical Engineering, 2007, Braslia, DF

${ }^{8}$ Myers, T.G., Mitchell, S.L, Muchatibayaa, G., Myers, M.Y, "A cubic heat balance integral method for one-dimensional melting of a finite thickness layer", International Journal of Heat and Mass Transfer, 2007

${ }^{9}$ Schwarz, H.A., "Über einen Grenzbergang durch alternierendes Verfahren" , Vierteljahrsschrift der Naturforschenden Gesellschaft in Zürich, 1870

${ }^{10}$ Gander, M.J., "Optimized Schwarz Methods" , SIAM J. , 2006

${ }^{11}$ Goldstein, R. J., Behbahni, A. I. and Heppelman, K. K., "Streamwise Distribution of the Recovery Factor and the Local Heat Transfer Coefficient to an impinging Circular Air Jet" Intl. J. of Heat and Mass Trans., Vol. 29, \#8, pp. 1227-1235, 1986

${ }^{12}$ Chauvin, R., Villedieu, P., Trontin, P., 'Theoretical and numerical study of iterative coupling algorithms applied to linear and non-linear heat transfer problems" Paper in preparation
} 